\title{
GESTÃO EDUCACIONAL INTEGRADA E SUAS CONTRIBUIÇÕES PARA A PRÁTICA PEDAGÓGICA
}

\author{
INTEGRATED EDUCATIONAL MANAGEMENT AND ITS CONTRIBUTIONS TO \\ PEDAGOGICAL PRACTICE
}

\author{
Cristiano Leonardo Martins Oliveira ${ }^{1}$ \\ Ivanéia Maria de Lima² \\ Maria José da Silva ${ }^{3}$ \\ Ronalda Adriana dos Santos da Silva ${ }^{4}$ \\ Diógenes José Gusmão Coutinho ${ }^{5}$
}

\begin{abstract}
RESUMO: Pretendeu-se analisar a quantidade de teses e dissertações, produzidas no período de 2016 a 2020, relatando sobre as contribuições de uma gestão integrada, por entre leituras bibliográficas que abrange a importância de suas funções para a prática pedagógica. Então foram encontrados 567 trabalhos e com critérios de inclusão e exclusão, decidiu-se apresentar as dissertações e teses. Elegemos 25 respondendo às abordagens em foco tendo como objetivo de entender a colaboração e eficácia da gestão integrada na escola.
\end{abstract}

Palavras-chave: Gestão integrada. Escolar. Participativa.

RESUME: It was intended to analyze the number of theses and dissertations produced in the period from 2016 to 2020, reporting on the contributions of an integrated management, among bibliographic readings that covers the importance of their functions for pedagogical practice. Then 567 papers were found and with inclusion and exclusion criteria, it was decided to present the dissertations and theses. We elected 25 responding to the approaches in focus with tobjective of understanding the collaboration and effectiveness of integrated management in the school.

Keywords: Integrated management. School. Participative.

\footnotetext{
${ }^{I}$ Licenciatura Plena em Geografia. Instituição: FAMASUL - Faculdade de Formação de Professores da Mata Sul. E-mail: cristianolmoliveira@gmail.com.

${ }^{2}$ Licenciatura em pedagogia, especialização em Gestão Escolar. Instituição: Universidade Vale do AcaraúUVA. E-mail: ivaneialima36@gmail.com.

3 Graduada em pedagogia, Especialização em Psicopedagoga Clínica e Institucional Instituição: UPE Universidade de Pernambuco. E-mail: mariajose-o45@hotmail.com

${ }^{4}$ Licenciatura Plena em Pedagogia, Especialização em Gestão e Psicopedagoga. Instituição: Universidade Vale do Acaraú- UVA. E-mail: adrysantos49@gmail.com.

5 Doutor em Biologia, pela Instituição Universidade Federal Rural de Pernambuco (UFRPE). E-mail: Gusmao.diogenes@gmail.com.
} 


\section{INTRODUÇÃO}

A gestão democrática é um princípio que está garantido na Lei de Diretrizes e Bases da Educação Nacional, Art. 3ํㅡㄹ Inciso VII, e também na Constituição Federal, em seu Artigo 206, Inciso VI. Assim, é possível avaliar a educação como um processo colaborativo e que demanda a participação de todos os elementos da comunidade escolar (COSTA, 2016, p.62)

As práticas de coordenação, supervisão, gerenciamento e controle exercidas pelos gestores sobre o trabalho docente e discente trazem, em seu conteúdo ideológico, fundamentos externos à escola e antagônicos à sua natureza, mas sob os quais se procura instituir uma nova cultura organizacional no ambiente escolar. É, pois, nessa direção, que as políticas estaduais para a educação recorrem à racionalidade técnica refletida, por exemplo, na concepção de gestão escolar profissionalizada e, ainda, nas subjetividades do diretor, líder capaz de motivar, estimular e conformar as subjetividades coletivas de seus liderados para a efetivação de uma gestão que se pretende democrática (OLIVEIRA, 2016, p. 158).

Haja vista que o ensino profissional integrado é uma modalidade que aborda a formação profissional, humanizada e emancipadora, na qual o trabalhador tenha domínio sobre como, o que e para quem produz, e que os conhecimentos desenvolvidos podem contribuir para a significação e contextualização de saberes dos conhecimentos das disciplinas da formação geral, ela também exige um novo perfil ao gestor. (OLIVEIRA, 2019, p. IIO).

A falta de um documento norteador e, também, de práticas corriqueiras de planejamento para a organização, bem como o funcionamento do currículo integrado, dificultam sua efetivação, [...] a falta de proatividade dos docentes em elaborar um planejamento diferenciado para cada sala, apoiados no discurso da sobrecarga, ou mesmo por não acreditarem na proposta, também, é fator fundamental para essa não implementação. Cabe aos professores, por meio da inovação e da intervenção pedagógica criativa, promover uma aprendizagem com maior grau de significado possível (OLIVEIRA, 2019, p. III).

Para tanto, tratar a educação como um caminho transformador, parece ter se tornado um desafio imenso as equipes gestoras atuais. Principalmente pela escola de hoje, que convive em uma sociedade que passa por mudanças sociais, políticas e econômicas constantes $[\ldots]$ em vista disso, o modelo e o funcionamento da escola torna-se questionável, 
já que, quando a escola idealiza formar para a cidadania, cabe a conscientização principalmente da gestão e de todos que circundam este espaço, quanto á necessidade de construção de uma politica pautada na reflexão crítica sobre a prática, na superação dos desafios e nas responsabilidades encontradas nas delegações de suas funções, como a organização pedagógica, planejamento, mediação de conflitos, incentivo, formação dos profissionais, entre outros (OLIVEIRA, 2017, p. 20).

\section{PERCURSO METODOLÓGICO}

Tratou-se de uma revisão sistemática de literatura onde foi realizada uma busca eletrônica de dissertações e teses que retratam sobre a gestão integrada escolar e suas contribuições para a prática pedagógica, publicadas no período entre os anos de 2016 a 2020 retirados da base de dados BDTD. As pesquisar foram obtidas a partir dos relatores "gestão integrada”, “escolar”, "participativa”, determinando como critérios de inclusão e exclusão as dissertações e teses em português. Decidiu-se pela revisão integrativa objetivando buscar conhecimentos de diversos autores, explorando a literatura atual, considerando a metodologia para assim, alcançando os resultados.

\section{RESULTADOS E DISCUSSÕES}

Foram encontrados 25 trabalhos publicados no período de 2016 a 2020. Dentre estes, 22 dissertações e 3 teses com predominância de dissertações no ano de 2016 e 2017.

Quadro I- Seleção dos trabalhos produzidos nos anos de 2016 a 2020

\begin{tabular}{|c|c|c|}
\hline ANO & DISSERTAÇÃO & TESE \\
\hline 2016 & o8 & o1 \\
\hline 2017 & 08 & oo \\
\hline 2018 & o1 & 02 \\
\hline 2019 & 05 & oo \\
\hline 2020 & 00 & 00 \\
\hline Total & 22 & 03 \\
\hline
\end{tabular}

Fonte: Elaborado pelo autor 
Dessa forma, esta revisão foi elaborada em dois tópicos: o primeiro abrange a compilação das obras pesquisadas e aspectos abordados e os segmentos de ensino da gestão integrada pesquisada, e no segundo tópico, apontaremos a importância de uma gestão integrada para a implementação de novas práticas pedagógicas, um diálogo com os autores destes trabalhos e a literatura fundamentadora do nosso estudo além das possíveis intervenções recomendadas pelos autores, que apresentaram os resultados.

\section{COMPILAÇÃO DAS OBRAS PESQUISADAS, ASPECTOS ABORDADOS E OS SEGMENTOS DE ENSINO INFLUENTE}

Foram inseridos o6 estudos que retratam a importância das possibilidades do uso do sistema integrado nas escolas. Entre o total de trabalhos publicados, 03 estudos abordaram a gestão integrada exclusivamente na escola e 04 retrataram a atuação pedagógica perante a gestão integrada e a implementação de sistemas de informações educacionais. Alguns exibiam a relevância de uma gestão democrática, outros retratavam sobre a trajetória da gestão escolar. Entretanto, ainda que alguns trabalhos abordem a necessidade de uma gestão integrada no ambiente escolar para melhor desenvolvimento de práticas pedagógicas, ainda há carência de ações educativas que adotem essa possibilidade em questão.

Quadro 2- Aspectos abordados no trabalho

\begin{tabular}{|c|c|}
\hline FOCO CENTRAL & PUBLICAÇÕES \\
\hline Gestão integrada na escola & 04 \\
\hline $\begin{array}{c}\text { Possibilidades do uso do sistema integrado dos gestores } \\
\text { educacionais }\end{array}$ & 02 \\
\hline Gestão democrática e desafios & 02 \\
\hline Trajetória de vida e práticas de gestão escolar & II \\
\hline Total & 02 \\
\hline
\end{tabular}

Fonte: Elaborado pelo autor

Maior parte das dissertações e teses pesquisadas descreviam sobre os desafios e possibilidades de uma gestão integral, e a trajetória percorrida pelos gestores para implementar novas práticas pedagógicas, diante disso é notório a necessidade de estratégias 
para uma gestão mais eficiente e de palestras para compartilhar as experiências adquiridas, desenvolvendo assim uma educação melhor.

Quadro 3- Segmentos de ensino pesquisados nas dissertações analisadas

\begin{tabular}{|l|c|}
\hline \multicolumn{1}{|c|}{ Segmentos de ensino } & Publicações que abordam \\
\hline Anos iniciais do fundamental II $\left(6^{\mathrm{o}}\right.$ ao $\left.9^{\underline{o}}\right)$ & 03 \\
\hline Ensino Médio & 02 \\
\hline
\end{tabular}

Fonte: Elaborado pelo autor

A partir dos trabalhos apresentados nas tabelas 2 e 3 apenas três tratam dos anos

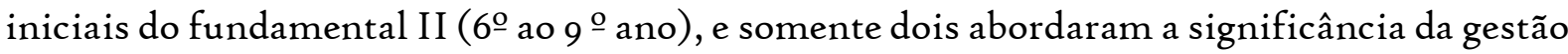
integrada escolar.

Diante das pesquisas realizadas e dos dados expostos nas tabelas, é perceptível a necessidade de estudos sobre uma gestão integrada e democrática desde a educação infantil até o ensino médio.

\begin{tabular}{|c|c|c|}
\hline Autor/Ano & Obra & Abordagens \\
\hline Silva, Tiago Lima e & $\begin{array}{l}\text { Possibilidades de uso do sistema } \\
\text { integrado de gestão educacional do } \\
\text { Amazonas na gestão das escolas. }\end{array}$ & $\begin{array}{l}\text { Objetivou-se compreender os } \\
\text { fatores utilizados para o } \\
\text { sistema integrado da gestão } \\
\text { educacional pelos gestores } \\
\text { escolares. }\end{array}$ \\
\hline Oliveira, Sheila Santos de & $\begin{array}{l}\text { A gestão integrada da escola no estado } \\
\text { do Rio de Janeiro: consensos e disputas. }\end{array}$ & $\begin{array}{l}\text { Analisar a gestão integrada nas } \\
\text { escolas, pretendendo } \\
\begin{array}{l}\text { apresentar as principais } \\
\text { contribuições. }\end{array}\end{array}$ \\
\hline Freitas, Islene da Conceição & $\begin{array}{l}\text { Análise de uma gestão integrada em } \\
\text { duas escolas estaduais do Rio de Janeiro. }\end{array}$ & $\begin{array}{l}\text { Investigar de que maneira os } \\
\text { docentes e discentes percebem } \\
\text { a inclusão de uma gestão } \\
\text { integrada no ambiente escolar. }\end{array}$ \\
\hline Costa, Marisa de Sant & $\begin{array}{l}\text { Monitoramento do sistema de gestão da } \\
\text { rede estadual do Rio de Janeiro pelo } \\
\text { comitê gestão integrada da escola - a } \\
\text { dinâmica de trabalho e seus desafios. }\end{array}$ & $\begin{array}{l}\text { Pretendeu-se verificar as ações } \\
\text { da rotina de uma gestão } \\
\text { integrada de uma escola do Rio } \\
\text { de Janeiro. }\end{array}$ \\
\hline $\begin{array}{l}\text { Oliveira, Fernanda Ramalho } \\
\text { de }\end{array}$ & $\begin{array}{l}\text { A atuação da gestão pedagógica na } \\
\text { integração curricular: proposta para } \\
\text { uma escola cearense. }\end{array}$ & $\begin{array}{l}\text { Inserir os jovens no mercado } \\
\text { de trabalho, atendendo a } \\
\text { necessidade de uma formação } \\
\text { profissional para os jovens. }\end{array}$ \\
\hline Carvalho, Mirian Valéria de & $\begin{array}{l}\text { Educação integral integrada em } \\
\text { uma escola do interior de Minas Gerais. }\end{array}$ & $\begin{array}{l}\text { Analisar como a gestão } \\
\text { compreende a proposta para } \\
\text { uma educação integral, }\end{array}$ \\
\hline
\end{tabular}




\begin{tabular}{|c|c|c|}
\hline & & $\begin{array}{l}\text { implementando estratégias } \\
\text { que superem os desafios } \\
\text { obtidos em sala de aula. }\end{array}$ \\
\hline $\begin{array}{lll}\text { Oliveira, } & \text { Juliana } & \text { Maria } \\
\text { Rosilda de } & & \\
\end{array}$ & $\begin{array}{l}\text { A gestão pedagógica nas escolas } \\
\text { integrais e a implantação do sistema de } \\
\text { informações educacionais de } \\
\text { Pernambuco: uma abordagem à luz da } \\
\text { perspectiva sociotécnica. }\end{array}$ & $\begin{array}{l}\text { Investigar as ações da gestão } \\
\text { pedagógica nas escolas que } \\
\text { possuem tempo integral, com a } \\
\text { implementação do sistema de } \\
\text { educação e informação de } \\
\text { Pernambuco. }\end{array}$ \\
\hline Vargas, Ana Lúcia Silva & $\begin{array}{l}\text { A gestão democrática } \\
\text { na escola municipal: } \\
\text { conselho escolar em questão. }\end{array}$ & $\begin{array}{l}\text { Averiguar as funções dos } \\
\text { gestores escolares para a } \\
\text { inserção de uma escola mais } \\
\text { democrática. }\end{array}$ \\
\hline $\begin{array}{lll}\text { Marise, } & \text { Regina } & \text { Barbosa } \\
\text { Uemura } & & \\
\end{array}$ & $\begin{array}{l}\text { Fatores determinantes no desempenho } \\
\text { das escolas de ensino profissionalizante } \\
\text { integrado ao médio: um estudo de caso } \\
\text { dos municípios de Cotia e São Roque. }\end{array}$ & $\begin{array}{l}\text { Identificar o que impulsiona o } \\
\text { desempenho dos alunos na } \\
\text { escola, fatores e especificações } \\
\text { da gestão escolar. }\end{array}$ \\
\hline Santos, Bianca Bezerra dos & $\begin{array}{l}\text { Trajetória de vida e práticas } \\
\text { de gestão escolar. }\end{array}$ & $\begin{array}{l}\text { Entender de que maneira a } \\
\text { trajetória dos gestores } \\
\text { influenciam em uma gestão } \\
\text { democrática e relaciona os } \\
\text { diferentes perfis de gestores. }\end{array}$ \\
\hline Maranesi, Tânia & $\begin{array}{l}\text { Gestão escolar: concepções } \\
\text { sentimentos que se entrecruzam. }\end{array}$ & $\begin{array}{l}\text { Verificar tanto o papel dos } \\
\text { gestores quanto dos } \\
\text { professores, identificando se os } \\
\text { sentimentos em ambiente } \\
\text { escolar interferem em suas } \\
\text { atuações. }\end{array}$ \\
\hline Ferreira, Rafael Silva & $\begin{array}{l}\text { A saída de estudantes antes da conclusão } \\
\text { do ensino médio integrado em uma } \\
\text { escola de educação profissional no } \\
\text { Ceará. }\end{array}$ & $\begin{array}{l}\text { Avaliar o que tem causado } \\
\text { desinteresse e reprovação nos } \\
\text { alunos, e implementar ações } \\
\text { que aumentem o índice de } \\
\text { concluintes no final do ano. }\end{array}$ \\
\hline Palú, Janete & $\begin{array}{l}\text { Planos de gestão escolar em Santa } \\
\text { Catarina: a gestão democrática em } \\
\text { questão. }\end{array}$ & $\begin{array}{l}\text { Compreender a inserção de } \\
\text { novas políticas de gestão } \\
\text { públicas, identificando as } \\
\text { propostas estabelecidas. }\end{array}$ \\
\hline $\begin{array}{l}\text { Falleiros, Simone Regina de } \\
\text { Oliveira Nascimento }\end{array}$ & $\begin{array}{l}\text { Do discurso à realidade da gestão } \\
\text { democrática: um estudo sobre a } \\
\text { participação da comunidade escolar em } \\
\text { uma escola pública do interior de São } \\
\text { Paulo. }\end{array}$ & $\begin{array}{l}\text { Analisar um conselho de } \\
\text { escola em uma cidade de São } \\
\text { Paulo, proporcionando ações } \\
\text { que possibilitem mudanças no } \\
\text { ambiente escolar diante de } \\
\text { desafios. }\end{array}$ \\
\hline $\begin{array}{l}\text { Campos, Claudia Gomes } \\
\text { Coelho }\end{array}$ & $\begin{array}{l}\text { A constituição da escola aprendente: um } \\
\text { estudo organizacional a partir das } \\
\text { relações entre gestão escolar e gestão do } \\
\text { conhecimento. }\end{array}$ & $\begin{array}{l}\text { Compreender o conhecimento } \\
\text { da gestão escolar, diante das } \\
\text { práticas utilizadas e produzir } \\
\text { metodologias para escolas } \\
\text { aprendentes. }\end{array}$ \\
\hline Silva, Ana Patricia Peinado e & $\begin{array}{l}\text { Sistema integrado de gestão educacional } \\
\text { do Amazonas: desafios e possibilidades } \\
\text { na utilização do módulo especial. }\end{array}$ & $\begin{array}{lcr}\text { Investigar } & \text { os fatores que } \\
\text { limitam a utilizar o módulo } \\
\text { especial para gestores, }\end{array}$ \\
\hline
\end{tabular}




\begin{tabular}{|c|c|c|}
\hline & & $\begin{array}{l}\text { impossibilitando-os } \\
\text { promover } \\
\text { pedagógicas. }\end{array}$ \\
\hline Pereira, Antonio Cezar & \begin{tabular}{lrrr} 
Democratização & & \multicolumn{2}{c}{ da gestão e } \\
conselho escolar: & o & caso & de \\
uma escola pública & no & município & de \\
Ipubi/ PE. & & & \\
\end{tabular} & $\begin{array}{l}\text { De que maneira é organizada a } \\
\text { participação da gestão escolar e } \\
\text { qual a contribuição do } \\
\text { conselho para esta gestão. }\end{array}$ \\
\hline Santos, Suzane Moura & $\begin{array}{l}\text { Educação integral e integrada em } \\
\text { uma escola estadual do Campo no } \\
\text { município de Januária/MG. }\end{array}$ & $\begin{array}{l}\text { Verificar as proposições de } \\
\text { ações mostradas na Educação } \\
\text { Integral e Integrada (EII) e } \\
\text { analisar os desafios e } \\
\text { possibilidades percorrida pelos } \\
\text { gestores. }\end{array}$ \\
\hline Schmitt, Diovanela Liara & $\begin{array}{l}\text { A gestão escolar e as implicações nas } \\
\text { ações didático pedagógicas } \mathrm{Da} \text { sala de } \\
\text { aula. }\end{array}$ & $\begin{array}{l}\text { Averiguar a gestão } \\
\text { participativa da escola, como } \\
\text { influência nas práticas } \\
\text { didático-pedagógicas } \\
\text { realizadas no ambiente escolar. }\end{array}$ \\
\hline Oliveira, Thiago Aparecido de & $\begin{array}{l}\text { A prática da gestão no cotidiano de } \\
\text { uma escola pública de Guarulhos. }\end{array}$ & $\begin{array}{l}\text { Entender e analisar as práticas } \\
\text { pedagógicas e os desafios de } \\
\text { entender os pais e os } \\
\text { funcionários e verificar se as } \\
\text { práticas pedagógicas utilizadas } \\
\text { estão dentro do ambiente } \\
\text { escolar. }\end{array}$ \\
\hline Neis, Dyogo Felype & $\begin{array}{l}\text { Processo estratégico escolar na prática: o } \\
\text { caso de uma escola de alto desempenho. }\end{array}$ & $\begin{array}{l}\text { Compreender como funciona o } \\
\text { processo de elaborar } \\
\text { estratégias pedagógicas em } \\
\text { uma escola de alto } \\
\text { desempenho. }\end{array}$ \\
\hline $\begin{array}{l}\text { D’Amico, Claudia da Silva } \\
\text { Martins }\end{array}$ & $\begin{array}{l}\text { Gestão democrática: ferramentas } \\
\begin{array}{ll}\text { desafios } & \text { encontrados } \\
\text { cinco escolas do Rio de Janeiro. }\end{array}\end{array}$ & $\begin{array}{l}\text { Tem como objetivo principal } \\
\text { investigar o uso de uma } \\
\text { ferramenta chamada "Índice } \\
\text { de Formação de Cidadania e } \\
\text { Responsabilidade Social", para } \\
\text { práticas e planejamento } \\
\text { pedagógicos, proporcionando } \\
\text { uma qualidade melhor. }\end{array}$ \\
\hline Gadelha, Aneloria Costa & $\begin{array}{l}\text { Desenvolvimento do programa mais } \\
\text { educação na escola estadual a: um estudo } \\
\text { de caso sobre a gestão pedagógica. }\end{array}$ & $\begin{array}{l}\text { Analisar como a gestão } \\
\text { pedagógica é estabelecida no } \\
\text { desenvolvimento do Programa } \\
\text { Mais Educação e incentivar o } \\
\text { uso de ações que promovam o } \\
\text { programa. }\end{array}$ \\
\hline Serafini, Rossonia Marini & $\begin{array}{l}\text { Os conselhos escolares na efetivação } \\
\text { da gestão democrática: alguns limites e } \\
\text { possibilidades. }\end{array}$ & $\begin{array}{l}\text { Buscar a democratização } \\
\text { escolar e analisar o processo da } \\
\text { gestão em relação a } \\
\text { descentralização de poder. }\end{array}$ \\
\hline Cajado, Leandra da Silva & $\begin{array}{lr}\text { Projetos pedagógicos e e } & \text { o } \\
\text { fracasso escolar: desafios } & \text { e } \\
\text { possibilidades } & \text { de } \\
\text { uma gestão colaborativa em uma escola } \\
\text { pública mineira. }\end{array}$ & $\begin{array}{l}\text { Compreender } \\
\text { desenvolvimento da gestão } \\
\text { escolar e a elaboração das } \\
\text { práticas pedagógicas e desafios } \\
\text { enfrentados. }\end{array}$ \\
\hline
\end{tabular}




\section{${ }_{4}$ CONSIDERAÇÕES FINAIS}

É perceptível que uma gestão integrada é de extrema eficácia para uma educação mais ampla e práticas pedagógicas bem elaboradas, entretanto há poucos estudos que retratam sobre a gestão integrada nos anos iniciais do ensino fundamental e no ensino médio, ressaltando práticas utilizadas e ações pedagógicas que possam desenvolver uma gestão democrática. Apesar disso, várias pesquisas se sobressaem acerca de uma gestão inclusiva, apresentando as possibilidades e desafios diante a gestão escolar.

Posto isto, é primordial a necessidade de ampliar o conhecimento sobre práticas pedagógicas e implementar ações que possibilitem uma educação mais abrangente.

\section{REFERÊNCIAS}

CAJADO, Leandra da Silva. Projetos pedagógicos e o fracasso escolar: desafios e possibilidades de uma gestão colaborativa em uma escola pública mineira. Juiz de Fora, 2018.

CAMPOS, Claudia Gomes Coelho. A constituição da escola aprendente: um estudo organizacional a partir das relações entre gestão escolar e gestão do conhecimento. João Pessoa, 2016.

CARVALHO, Mirian Valéria de. Educação integral integrada em uma escola do interior de Minas Gerais. Juiz de Fora, 2019.

COSTA, Marisa de Santana da. Monitoramento do sistema de gestão da rede estadual do rio de janeiro pelo comitê gestão integrada da escola - A dinâmica de trabalho e seus desafios. Juiz de Fora, 2016.

D’AMICO, Claudia da Silva Martins. Gestão democrática: ferramentas e desafios encontrados em cinco escolas do Rio de Janeiro. Juiz de Fora, 2018.

FALLEIROS, Simone Regina de Oliveira Nascimento. Do discurso à realidade da gestão democrática: um estudo sobre a participação da comunidade escolar em uma escola pública do interior de São Paulo. Franca, 2017.

FERREIRA, Rafael Silva. A saída de estudantes antes da conclusão do ensino médio integrado em uma escola de educação profissional no Ceará. Juiz de Fora, 2019. 
FREITAS, Islene da Conceição. Análise de uma gestão integrada em duas escolas estaduais do Rio de Janeiro. Rio de Janeiro, 2018.

GADELHA, Aneloria Costa. Desenvolvimento do programa mais educação na escola estadual a: um estudo de caso sobre a gestão pedagógica. Juiz de Fora, 2016.

MARANESI, Tânia. Gestão escolar: concepções e sentimentos que se entrecruzam. São Paulo, 2017.

MARISE, Regina Barbosa Uemura. Fatores determinantes no desempenho das escolas de ensino profissionalizante integrado ao médio: um estudo de caso dos municípios de Cotia e São Roque. São Paulo, 2016.

NEIS, Dyogo Felype. Processo estratégico escolar na prática: o caso de uma escola de alto desempenho. Florianópolis, 2018.

OLIVEIA, Fernanda Ramalho de. A atuação da gestão pedagógica na integração curricular: proposta para uma escola cearense. Juiz de Fora, 2019.

OLIVEIRA, Juliana Maria Rosilda de. A gestão pedagógica nas escolas integrais e a implantação do sistema de informações educacionais de Pernambuco: uma abordagem à luz da perspectiva sociotécnica. João Pessoa, 2016.

OLIVEIRA, Sheila Santos de. A gestão integrada da escola no estado do rio de janeiro (20II2014): consensos e disputas. Goiânia, 2016.

OLIVEIRA, Thiago Aparecido de. A prática da gestão no cotidiano de uma escola pública de Guarulhos. São Paulo, 2017.

PALÚ, Janete. Planos de gestão escolar em Santa Catarina: a gestão democrática em questão. Chapecó, 2019.

PEREIRA, Antonio Cezar. Democratização da gestão e conselho escolar: o caso de uma escola pública no município de Ipubi/ PE. João Pessoa, 2016.

SANTOS, Bianca Bezerra dos. Trajetória de vida e práticas de gestão escolar. Trajetória de vida e práticas de gestão escolar. Recife, 2017. 
SANTOS, Suzane Moura. Educação integral e integrada em uma escola estadual do Campo no município de Januária/MG. Juiz de Fora, 2019.

SCHMITT, Diovanela Liara. A gestão escolar e as implicações nas ações didático pedagógicas Da sala de aula. Ijuí, 2018.

SERAFINI, Rossonia Marini. Os conselhos escolares na efetivação da gestão democrática: alguns limites e possibilidades. Santa Maria, 2017.

SILVA, Ana Patricia Peinado e. Sistema integrado de gestão educacional do Amazonas: desafios e possibilidades na utilização do módulo especial. Juiz de Fora, 2017.

SILVA, Tiago Lima e. Possibilidades de uso do sistema integrado de gestão educacional do Amazonas na gestão das escolas. Juiz de Fora, 2016.

VARGAS, Ana Lúcia Silva. A gestão democrática na escola municipal: o conselho escolar em questão. Santa Maria, 2018. 